\title{
Magnet R\&D for the US LHC Accelerator Research Program (LARP)
}

\author{
S. A. Gourlay, G. Ambrosio, N. Andreev, M. Anerella, E. Barzi, R. Bossert, S. Caspi, D. R. \\ Dietderich, P. Ferracin, R. Gupta, A. Ghosh, A. R. Hafalia, C. R. Hannaford, M. Harrison, V. S. \\ Kashikhin, V. V. Kashikhin, A. F. Lietzke, S. Mattafirri, A. D. McInturff, F. Nobrega, I. Novitsky, G. \\ L. Sabbi, J. Schmazle, R. Stanek, D. Turrioni, P. Wanderer, R. Yamada, A.V. Zlobin
}

\begin{abstract}
In 2004, the US DOE established the LHC Accelerator Research Program (LARP) with the goal of developing a technology base for future upgrades of the LHC. The focus of the magnet program, which is a collaboration of three US laboratories, BNL, FNAL and LBNL, is on development of high gradient quadrupoles using $\mathrm{Nb}_{3} \mathrm{Sn}$ superconductor. Other program components address issues regarding magnet design, radiation-hard materials, long magnet scale-up, quench protection, fabrication techniques and conductor and cable $R \& D$. This paper presents an overall view of the program with emphasis on the current quadrupole project and outlines the long-term goals of the program.
\end{abstract}

Index Terms-Magnets, superconducting, accelerator, $\mathrm{Nb}_{3} \mathrm{Sn}$, quadrupole.

\section{INTRODUCTION}

$\mathrm{T}$ HE Large Hadron Collider (LHC) is designed for the collision of proton beams in four interaction regions (IRs) with a nominal energy of $7 \mathrm{TeV}$ per beam and two high-luminosity IRs of $10^{34} \mathrm{~cm}^{-2} \mathrm{~s}^{-1}$. The 1st generation lowbeta quadrupoles for the LHC IR inner triplets, based on $\mathrm{NbTi}$ superconductor, have been developed and are being fabricated by KEK and Fermilab in collaboration with CERN [1]. They provide a nominal field gradient of $205 \mathrm{~T} / \mathrm{m}$ in a $70-\mathrm{mm}$ bore and operate at $1.9 \mathrm{~K}$ in a high radiation environment.

Manuscript received September 20, 2005. This work was supported by the Director, Office of Energy Research, Office of High Energy and Nuclear Physics, High Energy Physics Division, U. S. Department of Energy, under Contract No. DE-AC02-05CH11231.

${ }^{1}$ S. A. Gourlay, S. Caspi, D. R. Dietderich, P. Ferracin, A. R. Hafalia, C. R. Hannaford, A. F. Lietzke, S. Mattafirri, A. D. McInturff and G. L. Sabbi are with Lawrence Berkeley National Lab, Berkeley, CA 94720 USA (phone: 510-486-4826; fax: 510-486-5310; e-mail: sagourlay@lbl.gov).

${ }^{2}$ G. Ambrosio, N. Andreev, E. Barzi, R. Bossert, V. S. Kashikhin, V. V. Kashikhin, F. Nobrega, I. Novitsky, D. Turrioni, R. Yamada, and A.V. Zlobin are with Fermilab National Accelerator Laboratory, Batavia, IL 60510-0500.

3 M. Anerella, A. Ghosh', R. Gupta, M. Harrison, J. Schmazle, and P. Wanderer are with Brookhaven National Laboratory, Upton, NY.
The U.S. LHC Accelerator Research Program (LARP) is a follow-on activity to the U.S. LHC Accelerator Construction Project, a collaboration of LBNL, BNL, and FNAL [2]. Participation in this program builds on the previous investment in the construction project and ensures continued development of domestic accelerator science and technology. The multi-year program includes participation in commissioning the accelerator and U.S.-provided components, design and construction of state-of-the-art beam instrumentation, accelerator physics studies, and design and technology development required for an upgrade of the interaction region magnet systems to increase luminosity.

The start of LHC operation is planned for 2007. However, preliminary studies of possible scenarios for future LHC upgrades have already been started at CERN and in the U.S. [3] aimed at increasing the luminosity to $3-10 \times L_{\text {nom }}$ or reaching the highest possible beam energy $E=(1.5-2) \times E_{\text {nom }}$. The ranges in both parameters reflect the uncertainties in actual LHC performance as well as unknown technical limitations.

The projected lifetime of the current IR magnets is six seven years at full luminosity. Combined with cost considerations, this makes replacement of the IR magnets an obvious scenario for an initial upgrade

The US National Laboratories (Berkeley Lab, Brookhaven and Fermilab) are now positioned to develop the next generation of high performance magnets for the IRs of the LHC, which can, by themselves, double or triple the luminosity, and which will be compatible with operation at full performance at a luminosity as high as $10^{35} \mathrm{~cm}^{-2} \mathrm{~s}^{-1}$. The same magnet technology also has the potential to allow a new machine to be built in the LHC tunnel with up to a factor of two increase in beam energy.

Steady improvements in the application of $\mathrm{Nb}_{3} \mathrm{Sn}$ technology have been made over the last several years [4]. The LARP magnet program is charged with answering the question of whether it can now be considered a viable material for practical high field accelerator magnets. High gradient, large aperture quadrupoles operating under high radiation induced heat loads, require superconductor with performance parameters provided by $\mathrm{Nb}_{3} \mathrm{Sn}$. Development 
of a $\mathrm{Nb}_{3} \mathrm{Sn}$-based technology that can be industrialized will require a long-term, aggressive $\mathrm{R} \& \mathrm{D}$ program. In addition to basic magnet development, the program outlined in this paper includes parallel development of ancillary technology to address issues that are crucial for operation of the magnets. Examples are; heat load due to secondary particles and synchrotron radiation, vacuum, quench protection, injection field quality and long coil fabrication.

The LHC luminosity upgrade provides a unique opportunity to operate magnets using $\mathrm{Nb}_{3} \mathrm{Sn}$ technology in an accelerator. LARP will also help to strengthen collaborative ties amongst the US Labs as well as with CERN and the international community.

\section{Program Structure}

\section{A. Issues}

The program goals are structured around the numerous issues related to development of a technological base necessary to meet performance and operational requirements. Some are generic to $\mathrm{Nb}_{3} \mathrm{Sn}$ accelerator magnet technology and others are specific to LARP applications.

\section{1) Conductor and Cable}

The demanding operational parameters of the upgrade magnets require the use of superconducting materials substantially beyond NbTi. Recent progress in the development of $\mathrm{Nb}_{3} \mathrm{Sn}$ magnets has encouraged the prospects for its use in LHC upgrades. However, even though it has been available for more than 40 years, $\mathrm{Nb}_{3} \mathrm{Sn}$ technology, as applied to accelerator magnets, is still far from fully developed and success is founded on high performance conductor. While critical current density has improved dramatically since the start of the DOE sponsored Conductor Development Program (CDP), there are still several important issues remaining, such as reducing effective filament diameter, increasing RRR and piece length, while maintaining the high critical current density. The US DOE, Office of High Energy Physics has been funding the development of $\mathrm{Nb}_{3} \mathrm{Sn}$ through a program established in 1999.

The first phase of a modest conductor development program, initiated by the U.S. Department of Energy, has resulted in readily available conductor with critical current densities over $3 \mathrm{kA} / \mathrm{mm}^{2} @ 12$ Tesla and $4.2 \mathrm{~K}$ [5]. A complete list of the target parameters are shown in Table 1.

\section{2) Coil Design}

There are several possible limitations to achieving higher luminosity and a number of upgrade options have been proposed. The actual configuration for an IR upgrade will not be known until after significant experience is gained with operating the existing IRs. However, in all cases, large bore quadrupoles are required, and as an initial target, the program
TABLE I

TECHNICAL AND COST PERFORMANCE GOALS OF THE US/HEP CONDUCTOR DEVELOPMENT PROGRAM

\begin{tabular}{ll}
\hline \hline Specification & Target value \\
$\mathrm{J}_{\mathrm{c}}$ (noncopper,12T, 4.2K) & $3000 \mathrm{~A} / \mathrm{mm}^{2}$ \\
Effective filament size & Less than 40 microns \\
& Greater than $10 \mathrm{~km}$ in dia. \\
of 0.3 to $1.0 \mathrm{~mm}$ \\
Minimum piece length & Less than $\$ 1.50 / \mathrm{kA}-\mathrm{m}$ \\
Wire cost & $(12 \mathrm{~T}, 4.2 \mathrm{~K})$ \\
Heat treatment times & Less than $200 \mathrm{hrs}$ \\
\hline \hline
\end{tabular}

will focus on development of a $90 \mathrm{~mm}$ bore and a gradient equal to or greater than the current design. Other configurations of aperture and gradient will be considered depending on the needs of the upgrade. Figure 1 illustrates the available parameter space. A staged approach will be used, beginning with a simple two-layer coil design providing field gradients in the range of $220-250 \mathrm{~T} / \mathrm{m}$ (peak field of $11.2-12.6 \mathrm{~T}$ ) and moving to more complex coil designs to increase the gradient and/or operating margin. The latter part of the program may consider increasing the aperture depending on early results of the program and ongoing studies.

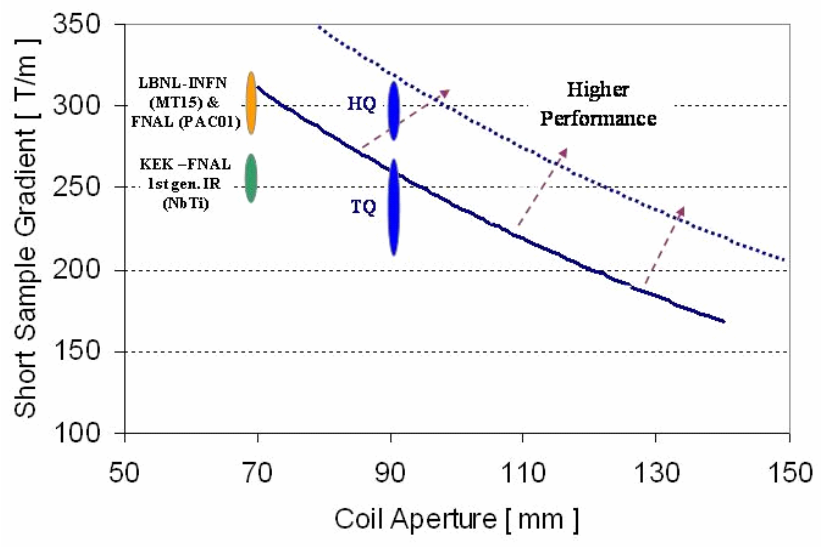

Figure 1. Gradient vs aperture. Vertical line indicates gradient range for $45 \mathrm{~mm}$ radius bore.

\section{3) Fabrication}

The fabrication process is based on the wind and react approach. The Rutherford cable is insulated with either an S2 glass sleeve or wrapped with ceramic fiber tape. The coil is wound and then treated with a ceramic binder, cured to size in a press to facilitate handling and inserted into a reaction fixture. After reaction the coil is impregnated with CTD$101^{\circledR}$, an epoxy produced by Composite Technology Development. This general fabrication process has been used successfully for short models but has not been scaled to coils longer than 1 meter. Length scale-up, in terms of reacting, impregnating and handling long coils, is considered to be a critical issue and is one of the three main goals of the first phase of the program. 


\section{4) Mechanical Structure and Assembly}

$\mathrm{Nb}_{3} \mathrm{Sn}$ is a brittle compound and requires careful control of stress throughout assembly, cool-down and excitation. The current accepted working limit is $200 \mathrm{MPa}$. The program is pursuing two parallel approaches; conventional collars and yoke and an aluminum shell-based structure. Each of these has advantages and disadvantages that will be described later.

\section{5) Operation in a high radiation environment}

An increase in luminosity comes with a corresponding increase in radiation from the IRs. The development and use of more radiation-hard materials such as cyanate esters and enhanced cooling schemes to deal with the high radiationinduced heat loads will be an ongoing component of the program that will intensify as a technological base is established.

\section{B. Program Goals}

The above issues and others that emerge during the course of the R\&D program are addressed by the general goal of the program to "demonstrate by 2009 that $\mathrm{Nb}_{3} \mathrm{Sn}$ magnets are a viable choice for an LHC IR upgrade.” This goal has three components that are implemented by a combination of model magnets with specific targets.

\section{1) Predictable and reproducible performance}

The viability of any new technology application is judged on the consistent reproducibility of performance and operating parameters. This component of the program is expressed through the construction of a series of “Technology Quadrupoles” (TQs). The TQs are based on a two-layer, cos-theta geometry with a $90 \mathrm{~mm}$ bore. The first series uses Modified Jelly Roll (MJR) conductor with a $\mathrm{J}_{\mathrm{c}}$ of approximately 2,000 $\mathrm{A} / \mathrm{mm}^{2}$ at $12 \mathrm{~T}$ and $4.2 \mathrm{~K}$. The expected maximum gradient is $215 \mathrm{~T} / \mathrm{m}$ at $4.2 \mathrm{~K}(235 \mathrm{~T} / \mathrm{m}$ at $1.9 \mathrm{~K})$. The TQs are also used to compare two support structure designs; TQC01, based on stainless steel collars supported by an iron yoke (Fig. 2) and thick stainless steel skin and TQS01, a shell-based structure using bladders for precise, low-level pre-stress control and interference keys to retain the pre-stress, allowing bladder removal (Fig. 3). A tensioned aluminum shell compresses internal iron and coil components developing substantial pre-stress on cool-down [6, 7].

\section{2) Long magnet fabrication}

Development of fabrication, handling and assembly techniques required for the construction of long magnets will begin with scale-up of simple racetrack coils. A nominal length of 4 meters was chosen for the "long racetrack" (LR) coils, and later adjusted to $3.6 \mathrm{~m}$ so that the magnet would fit in available vertical test dewars at both BNL and Fermilab. The LR coils are based on a well-developed 2-layer design, contained in a simple aluminum shell-type structure used extensively in the LBNL magnet program and similar to that used for TQS01 [7,8,9], Fig. 4. Successful completion of this

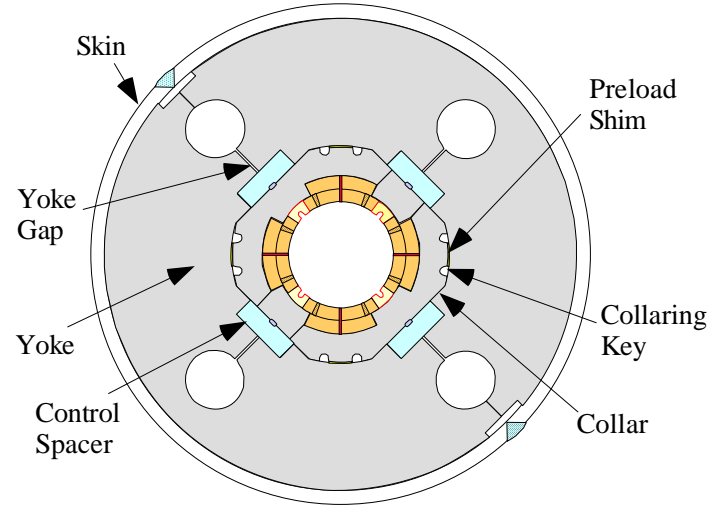

Figure 2. TQC mechanical structure.

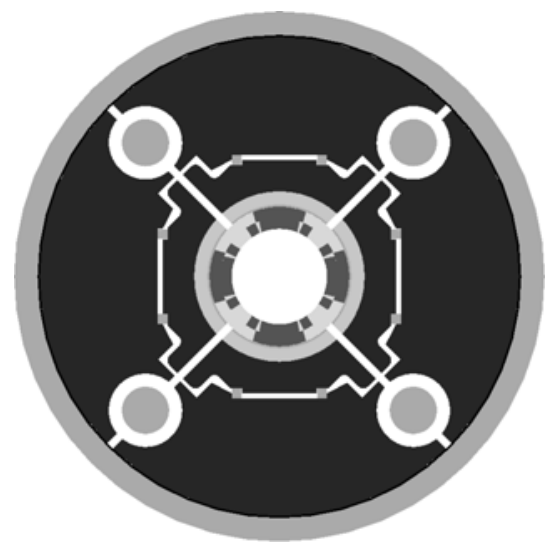

Figure 3. TQS mechanical structure.

program will be followed by construction of a long (3.6 m) cos-theta quadrupole (LQ) based on the TQ cross section.

\section{3) High gradient in a large aperture}

In FY06 work will begin on the conceptual design of a "High gradient quadrupole" (HQ) that will explore the ultimate performance limits in terms of peak fields, forces and stresses. The HQ design will be selected based on analysis of different options as well as feedback from ongoing studies in the areas of materials, model magnet and supporting R\&D. A $90 \mathrm{~mm}$ aperture over a $1 \mathrm{~m}$ length was deemed sufficient to investigate the critical design and technology issues while being cost-efficient and offering good compatibility with existing tooling. It is expected that the HQ design will provide coil peak fields of the order of 15 Tesla, corresponding to gradients of about $300 \mathrm{~T} / \mathrm{m}$ in the 90 $\mathrm{mm}$ aperture.

\section{Program Organization}

The above activities are integrated and organized around four general areas; Design Studies, Model Magnet R\&D, Supporting R\&D and Materials. They form the basis of a Work Breakdown Structure and are functionally represented by working groups, made up of members of the collaborating laboratories. The working groups are coordinated by "Level 


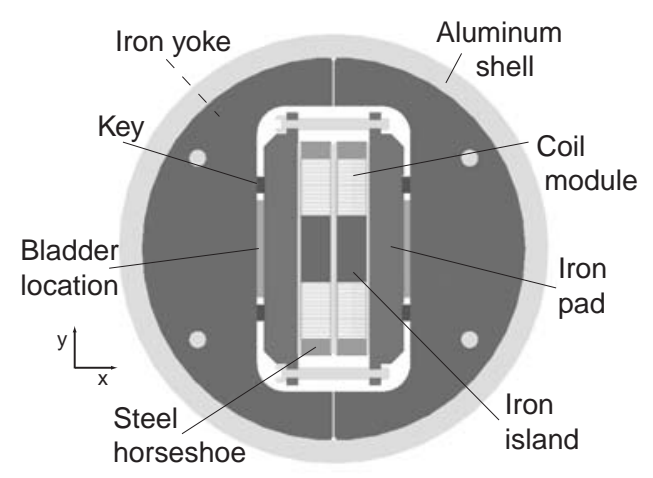

Figure 4. Sub-scale magnet cross section.

2" managers who also oversee the various tasks in their respective areas. The responsibility for coordination and execution of a particular task resides with specific "Task Managers.”

\section{1) Design Studies}

The Design Studies activity is generally intended to provide input on magnet parameters and lay the groundwork for the program. It covers a broad range of activities; conceptual magnet designs, radiation deposition studies, cryogenic and cooling issues and provides an interface for communication with the Accelerator Physics section of LARP.

\section{2) Model Magnet $R \& D$}

Model Magnet R\&D integrates input from the other three areas to produce model magnets that directly apply to the program goals. The current focus is on the TQs and it will eventually house activities to build the LQs and HQs.

\section{3) Supporting $R \& D$}

Supporting $R \& D$ covers a wide range of technical issues, primarily related to fabrication and operation. The largest task in this area is long magnet scale-up. Other tasks include sub-scale quadrupoles (SQs) to study performance-related issues, verify analysis models, incorporate rad-hard materials and support structure development[10].

\section{4) Materials}

Conductor is a critical component of the program. The responsibility of the Materials activity is two-fold; provide sufficient quantities of well-characterized strand for magnet development and carry on the necessary R\&D to support development of material that will ultimately be used for the upgrade [11].

\section{CONCLUSION}

The US LHC Accelerator Research Program has launched an aggressive program to develop accelerator magnet technology for upgrades that will enhance the physics potential of the LHC. The LARP is an excellent opportunity to extend high field accelerator magnet technology, and to create and strengthen national and international collaboration that will continue into future projects.

\section{REFERENCES}

[1] R. Ostojic, M. Karppinen, CERN; R. Bossert, J. Dimarco, S. Feher, J. Kerby, M. Lamm, T. Nicol, Fermilab; N. Kimura, T. Nakamoto, KEK, "The Production of the Low-Beta Triplets for the LHC", these proceedings.

[2] Kephart, R., et al.,“The U.S. LHC Accelerator Research Program: A Proposal,” http://www-td.fnal.gov/LHC/USLARP.html

[3] A comprehensive bibliography can be found at http://carehhh.web.cern.ch/care-hhh/publications.htm

[4] Gourlay, S.A., "High Field Magnet R\&D in the USA," presented at the 18th International Conference on Magnet Technology, October 20-24, 2003, Morioka, Japan., IEEE Trans. Appl. Supercond. Vol. 14, No. 2, June 2004, pp. 333-338, SC-MAG \#813, LBNL-53128, 6/24/2003.

[5] R.M. Scanlan, D.R. Dietderich, and S.A Gourlay, "A New Generation $\mathrm{Nb}_{3} \mathrm{Sn}$ Wire, and the Prospects for its use in Particle Accelerators", Advances in Cryogenic Engineering: Transactions of the International Cryogenic Materials conference - ICMC, Vol. 50, pp. 349 - 357. Cryogenic Engineering and International Cryogenic Materials Conference, Anchorage, Alaska. September 22 - 26, 2003, SC-MAG 3831, LBNL-54374.

[6] R.C. Bossert et al, "Development of TQC01, a $90 \mathrm{~mm} \mathrm{Nb}_{3} \mathrm{Sn}$ Model Quadrupole for LHC Upgrade Based on Stainless Steel Collar,” these proceedings.

[7] S. Caspi, et al, "Design and Construction of TQS01, $190 \mathrm{~mm} \mathrm{Nb}_{3} \mathrm{Sn}$ Model Quadrupole for LHC Luminosity Upgrade Based on a Key and Bladder Assembly," these proceedings.

[8] Bartlett, S.E., Caspi, S., Dietderich, D.R., Ferracin, P., Gourlay, S.A., Hannaford, C.R., Hafalia, A.R., Lietzke, A.F., Mattafirri, S., Sabbi, G., "An R\&D Approach to the Development of Long $\mathrm{Nb}_{3} \mathrm{Sn}$ Accelerator Magnets Using the Key and Bladder Technology," Applied Superconductivity Conference 2004 (October 3-8, 2004, Jacksonville, FL), IEEE Trans. Appl. Supercond. Vol. 15, No. 2, June 2005, pp. 1136 - 1139, LBNL-54893.

[9] S. Caspi, L, Chiesa, M. Coccoli, D.R. Dietderich, S.A. Gourlay, R. Hafalia, A.F. Lietzke, J.W. O'Neill, G. Sabbi, R.M. Scanlan, "An Approach for Faster High Field Magnet Technology Development,” Applied Superconductivity Conference 2002 (Houston, TX, August 4 9, 2002), IEEE Trans. Appl. Supercond. Vol. 13, No. 2, June 2003, pp. 1258 - 1261, SC-MAG \#773 , LBNL-49918.

[10] P. Ferraqcin et al, "Assembly and Test of SQ01b, a Nb ${ }_{3}$ Sn Racetrack Quadrupole Magnet for the LHC Accelerator Research Program,” these proceedings.

[11] E. Barzi et al, "Round and Extracted Strand Tests for LARP Magnet R\&D," these proceedings. 